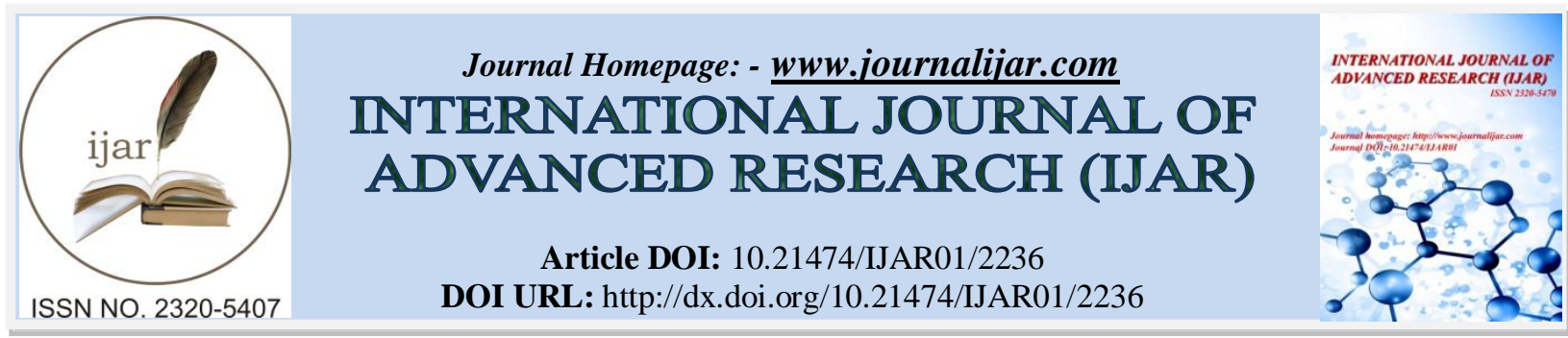

RESEARCH ARTICLE

\title{
Study of Cyclic Voltammograms and Polarograms obtained from Complex of Aluminium with Poly Methyl Aniline (PMA).
}

Anubha Vijay Pandya.

Professor and Head of the Department of Chemical Sciences Christian Eminent College Indore India.

\section{Manuscript Info}

Manuscript History

Received: 29 September 2016

Final Accepted: 30 October 2016

Published: November 2016

Key words:-

Cyclic voltammetry, PMA, half wave potential, diffusion current dropping mercury electrode

\section{Abstract}

In this paper Cyclic Voltammetric parameters and Polarographic parameters for PMA i.e. Poly Methyl Aniline and its Complex formation with $\mathrm{Al}$ have been presented. To find out the number of electrons involved in the electrode process cyclic voltammetric studies have been performed. Sets of solutions containing varying concentration of each of the polymers in $0.1 \mathrm{M}$ potassium chloride (overall concentration) were prepared and the $\mathrm{pH}$ was adjusted to $8.0 \pm$ 1 and scan rate was $40 \mathrm{mVs}-1$, similar sets of poly methyl aniline $-\mathrm{Al}$ complex of Various concentration were prepared Cyclic voltammograms of these sets were recorded on the Pulse polarograph CL90 . Fig- 2.2and 2.7 show the cyclic voltammogramms of PMA, Al -PMA complexes respectively. The cyclic voltammetric data for these species have been tabulated in tables.

Copy Right, IJAR, 2016,. All rights reserved.

\section{Introduction:-}

The development of the field of conducting polymers has continued to accelerate at an unexpectedly rapid rate. in this development there have been contributions from a wide spectrum of scientists such as chemists ,physicists, polymer materials scientists, spectroscopists, electronic and electrical engineers ,thereby making this field as one of the most interdisciplinary fields of science today . by now these polymers are showing commercial promise in such areas as power equipment, light weight and rechargeable batteries ,micro machines, adhesives and many more applications have been proposed using these exciting systems. Polymer is a generic name given to a vast number of materials which exist in countless forms and numbers of materials which exist in countless forms and numbers. Because of a very large number and types of atoms present in their molecules, polymers can have different chemical structures, physical properties, mechanical behavior, thermal ways etc.Focusing attention on such an emerging field and taking stock of the progress made in this field, would give further fillip to research in this field.. All the Chemicals used were of anala $\mathrm{R} / \mathrm{BDH}$ grade. $0.01 \mathrm{M}$ metal $(\mathrm{Al}++$ ) solutions were prepared by dissolving the requisite quantity of their soluble salts in double distilled water $0.1 \mathrm{M}$ Poly Methyl Aniline solutions were prepared in small amount of hydrochloric acid diluted to required volume with distilled water 1. Experimental sets of solutions containing overall concentration of supporting electrolyte $(\mathrm{KCl})$ and Metal ion fixed at $0.1 \mathrm{M}$ and $1.0 \mathrm{mM}$ respectively. Whereas in other sets in addition to the above supporting electrolyte and metal ion concentration of each polymer (legend) was varied.Polarograms were recorded on an ELICO (Hyderabad) pulse polarograph Model CL-90 having a dropping mercury electrode (DME) a saturated calomel electrode (SCE) a working electrode as a working electrode reference electrode respectively.

Corresponding Author:- Anubha Vijay Pandya.

Address:- Professor and Head of the Department of Chemical Sciences Christian Eminent College Indore India. 


\section{Materials \& Methods:-}

Poly Methyl Aniline sulphate was prepared by chemical method applying oxidant (Potassium dichromate) the polymerization of 0.4 moles of methyl aniline in 1 lit. of $1 \mathrm{M}$ sulphuric acid was affected using $1 \mathrm{~g}$ equivalent of the potassium dichromate a precipitate was separated, washed, dried and weighed as poly Methyl Aniline sulphate Poly Methyl Aniline Chloride was prepared by equilibrating the Poly Methyl Aniline sulphate with $1 \mathrm{M} \mathrm{HCl}$ for about 10 hrs. The mass so obtained was separated, washed and dried and weighed as Poly Methyl Aniline Chloride. Preparation of Poly Methyl Aniline complex .An adequate quantity of the Poly Methyl Aniline host and the inorganic salts of Al were separately dissolved in suitable solvent (e.g. acetonitrile). The two solutions were then mixed and after stirring the solvent evaporated slowly to finally obtain powder form of Poly Methyl Aniline - Al complexes.

\section{Result \& Discussion:-}

It clearly says that in case of Poly Methyl Aniline - Al complexes. (Al-PMA),the Epc-Epa i.e.cathodic and anodic peak potential values, indicating the involvement of 3,2 and 3 electrons in the reversible electrode reduction process of the said species respectively5.the Ipc and Ipa values are also tabulated in tables-1.1and table 1.2 which2 also supports this argument 8 . Characteristic nature of E1/2 of metal is changed when it forms a complex with some legend. It has been observed by Lingan 1 that E1/2 of the metal ion is shifted to more electronegative value on complex formation and its diffusion current is shortened 10. Conclusion On gradual increase of the polymer concentration the half wave potential of the metal ion shifted to more negative value in each case and the diffusion current also decreased which revealed complex formation of the Al metal ion with Poly Methyl Aniline7. To determine the composition and stability constants of binary complex plots of $\Delta \mathrm{E} 1 / 2$ (shift in half wave potential, $\mathrm{E} 1 / 2=(\mathrm{E} 1 / 2) \mathrm{c}-(\mathrm{E} 1 / 2) \mathrm{s}$ against $\log \mathrm{Cx}$ (logarithm of the complaxation of the legend )were drawn. The plots were linear showing the formation of single complex species in solution .Lingane treatment of the observed polarographic data revealed 1: $2 \mathrm{Al}$ : PMA complex formation in each case with formation constant $\log \mathrm{B}=13.146$ for Al (III) PANI Polarographic parameters of Al- Poly Methyl Aniline complex formation is confirmed by its shortened diffusion current. Lingane has given a method for the study of dissociation /formation constant of the complex using polarographic method 9.Q In selt observed that the temperature dependence of the Poly Methyl Aniline film voltammetric response in aqueous and non aqueous, only a very slight shift into the direction of more negative potentials $(\mathrm{Ca}-10 \mathrm{mV})$ and a small increase in the temperature is increased by 300C 4 . DME had a characteristics of $m=2.33$ mgs- $1 \mathrm{t}=3.03$ at $40 \mathrm{~cm}$ effective height of mercury column, $\mathrm{m} 2 / 3 \mathrm{t} 1 / 6=2.13 \mathrm{mg} 2 / 3 \mathrm{~s}-1 / 2$

Table 1:- Some Cyclic Voltammetric and Polarographic parameters observed for Poly Methyl Aniline (PMA)

\begin{tabular}{|l|l|l|l|l|l|l|l|l|}
\hline $\begin{array}{l}\text { Concentration } \\
\mathrm{mM}\end{array}$ & Id $(\mu \mathrm{A})$ & $\begin{array}{l}\text { E1/2 V } \\
\text { vs. SCE }\end{array}$ & Epa (V) & Epc (V) & $\begin{array}{l}\text { Epc - } \\
\text { Epa (V) }\end{array}$ & Ipa $(\mu \mathrm{A})$ & Ipc $(\mu \mathrm{A})$ & $\begin{array}{l}\text { No. of } \\
\text { electrons } \\
\text { involved }\end{array}$ \\
\hline 0.1 & 1.1 & -0.66 & 0.62 & -0.64 & -0.02 & 0.24 & 0.30 & 3 \\
\hline 0.2 & 1.0 & -0.64 & 0.62 & -0.64 & -0.02 & 0.22 & 0.24 & 3 \\
\hline 0.3 & 0.84 & -0.65 & 0.62 & -0.64 & -0.02 & 0.20 & 0.20 & 3 \\
\hline
\end{tabular}

Table 2:- Some Cyclic Voltammetric and Polarographic parameters observed for Al (III)- Poly Methyl Aniline

\begin{tabular}{|c|c|c|c|c|c|c|c|c|}
\hline \multicolumn{9}{|c|}{ (Al-PMA) complex } \\
\hline $\begin{array}{l}\text { Concentration } \\
m M\end{array}$ & $\begin{array}{l}I d \\
(\mu A)\end{array}$ & $\begin{array}{ll}E_{1 / 2} & \\
V & v s \\
S C E & \end{array}$ & $\begin{array}{l}E_{p a} \\
(V)\end{array}$ & $\begin{array}{l}E_{p c} \\
(V)\end{array}$ & $\begin{array}{l}\boldsymbol{E}_{p c}-\boldsymbol{E}_{p a} \\
(V)\end{array}$ & $\begin{array}{l}\text { Ipa } \\
(\mu A)\end{array}$ & $\begin{array}{l}\text { Ipc } \\
(\mu A)\end{array}$ & $\begin{array}{l}\text { No. } \quad \text { of } \\
\text { electrons } \\
\text { involved }\end{array}$ \\
\hline 0.1 & 0.96 & -1.08 & -1.06 & -1.10 & -0.04 & 0.20 & 0.26 & 2 \\
\hline 0.2 & 1.06 & -1.1 & -1.05 & -1.08 & -0.3 & 0.20 & 0.24 & 2 \\
\hline 0.3 & 0.9 & -1.08 & -1.05 & -1.08 & -0.3 & 0.20 & 0.28 & 2 \\
\hline
\end{tabular}




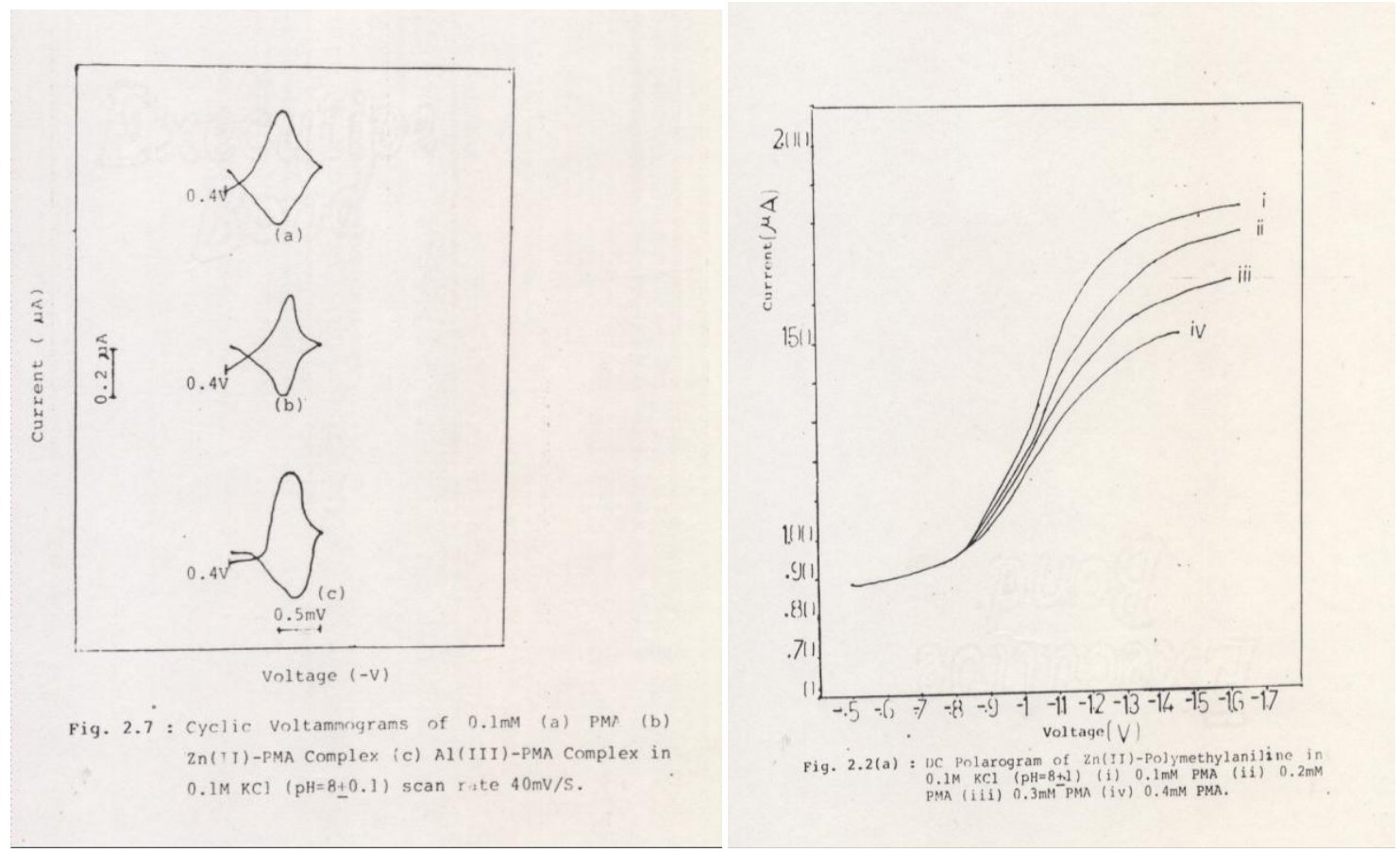

Picture of Original Cyclic Voltammograms recorded using pulse polarograph CL-90.

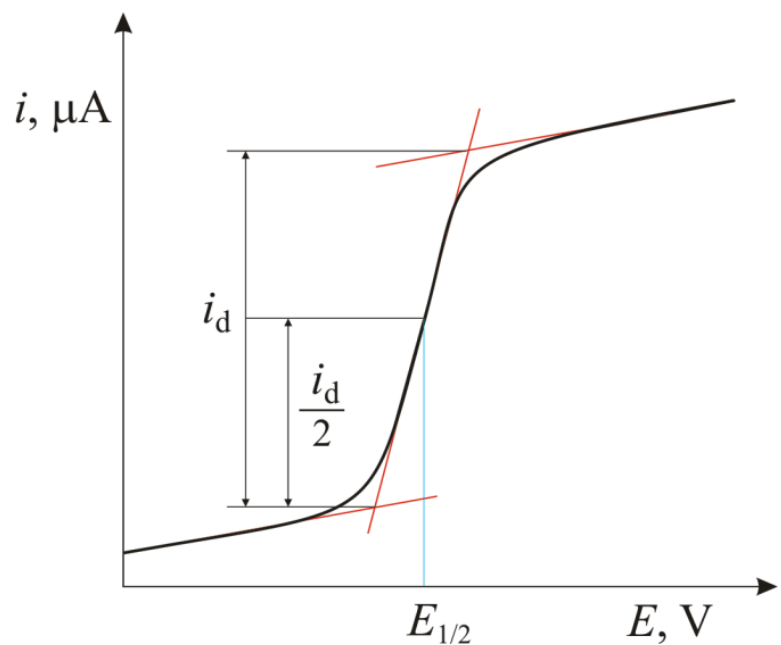

Survey of literature:-

Expected polarogram with standard electrically conducting material.

W.John Albery, et.al have used electrode 3. Such as Poly Methyl Aniline, polypyrol.Polyaniline and polythiophene. They showed that the behavior of the different polymers is similar and may be explained by a chemical model involving localized redox species with two possible conformations of the polymer. The temperature dependence of the Poly Methyl Aniline film voltammetric response in aqueous and non aqueous media has been investigated by G.Inzelt 2 .He observed that only a very slight shift into the direction of more negative potentials in the peak potentials $(\mathrm{Ca}-10 \mathrm{mv})$ and a small increase in the peak current as the temperature is increased by $300 \mathrm{C}$. Youn Chaol on Park Yong Woo studied behavior Poly Methyl Aniline and found that the electrons are moving in and out changing the Poly Methyl Aniline structure from one form to the another form C. Herold 12 Yazmi, D.Billaud attempted study of sodium doped polyparaphenylene film, John Alberry, et.al 


\section{References:-}

1. J.Lingane, Chem.Rev. 29,1(1941)

2. Youn Chaol on, Park yong Woo. Hanguk Multi.Hakh-oechl, Ungyong Mulli, 2(3), 256- 60(Korean)(1989).

3. C. Herold, R.Yazami, D.Billaud, Terre (France)

4. W.John Albery, Zheng Chem., Benjamin R.Horrocks, Andrew R. Mount and Peter. J.Wilson, David Bloor Andew T. Monkmann, C.Michal Elliot, Fabradar Chem. Soc. 88, 247-259(1989)

5. Bruno Scrosati, solid state ionic devices, 18-23 July 131-133(1988)

6. V.R. Gwariker, N.V. Vishwanathan, Jaydev Sridhar, polymer Science Willey Eastern Ltd.(New Delhi),(1990)

7. C.A. Vincent, Progress in solid state Chemistry,17,145,(1987)

8. Youn Chaol on ,Park yong Woo. Hanguk Multi.Hakh-oechl,Ungyong Mulli, 2(3), 256- 60(Korean)(1989).

9. A.Bond, Modern Polarographic Methods in analytical Chemistry, Macel Dekker, NewYork (1980)

10. H.Willard, W.Merrit, J.R. and J.A. Deen, Instrumental Methods of Analysis (EWP Ltd. New Delhi) (1980). 